\title{
Assessing the Snow Disaster and Disaster Resistance Capability for Spring 2019 in China's Three-River Headwaters Region
}

\author{
Quanqin Shao ${ }^{1,2, *}$, Guobo Liu ${ }^{1,2}$, Xiaodong $\mathrm{Li}^{3}{ }^{3}$, Haibo Huang ${ }^{1}$, Jiangwen Fan ${ }^{1}$, Liya Wang ${ }^{4}$, \\ Jiyuan Liu ${ }^{1}$ and Xingjian Guo ${ }^{1,2}$ (D) \\ 1 Key Laboratory of Land Surface Pattern and Simulation, The Institute of Geographical Sciences and Natural \\ Resources Research, Chinese Academy of Sciences, Beijing 100101, China; liugb.17b@igsnrr.ac.cn (G.L.); \\ huanghb@lreis.ac.cn (H.H.); fanjw@igsnrr.ac.cn (J.F.); liujy@igsnrr.ac.cn (J.L.); guoxj.15b@igsnrr.ac.cn (X.G.) \\ Alpine of Resource and Environment, University of Chinese Academy of Sciences, Beijing 100049, China \\ Alpine Ecological Meteorological Laboratory, Qinghai Provincial Institute of Meteorological Sciences, \\ Xining 810001, China; 550381lxd@163.com \\ 4 Grassland Survey Planning and Design Section, Qinghai Provincial Station of Grassland, Xining 810008, \\ China; wly1123@163.com \\ * Correspondence: shaoqq@igsnrr.ac.cn; Tel.: +86-010-6483-6525
}

Received: 11 October 2019; Accepted: 12 November 2019; Published: 15 November 2019

\begin{abstract}
Frequent snowfall and low temperatures led to a considerable snow disaster in some areas of China's Three-River Headwaters Region (TRHR) in Qinghai province in the spring of 2019, exerting a considerably negative influence on animal husbandry production in local grasslands. Based on a model of snow disaster classification and quantitative estimations of disaster-stricken animal husbandry, we propose a comprehensive disaster resistance capability index (CDRCI) using remote sensing, ground monitoring, and statistical investigations. With a comprehensive assessment of the space distribution and the magnitude of snow disasters, combined with a quantitative determination of disaster-stricken animal husbandry, the proposed CDRCI calculates how grassland animal husbandry is affected by snow disasters in different counties of the TRHR. The results indicate that approximately 2.31 million sheep and yaks were affected by moderate to severe snow disasters in the TRHR, accounting for $78.3 \%$ of the total livestock in the affected region. Of these affected livestock, approximately 1.54 million sheep and yaks were specifically affected by severe snow disasters, accounting for $52.1 \%$ of the total number of livestock. The CDRCIs for grassland animal husbandry in both Yushu and were moderate, being higher for the former than for the latter. We confirmed that the proposed CDRCI can accurately evaluate the magnitude of snow disasters in terms of how they affect grassland animal husbandry. The CDRCI is a way of relating the number of animal deaths to spatial disaster prevention and resistance. We expect that this research will provide important theoretical support for formulating snow disaster resistance policy, for example for increasing the construction of grassland animal husbandry infrastructure as well as providing greater stored forage material.
\end{abstract}

Keywords: Three-River Headwaters Region; snow disaster; grassland animal husbandry production; comprehensive snow disaster resistance capability; policy suggestions

\section{Introduction}

As the source of three main rivers in China-the Yangtze, Yellow, and LanSang Rivers-the Three-River Headwaters Region (TRHR) functions as an important barrier that protects China's ecological environment [1-3], and forms a major part of the Qinghai Pastoral Area, one of the four largest pastoral areas in China. Grassland animal husbandry is of importance for industrial activities 
in the region [2]. Snow disasters refer to times when pasture land (especially in animal husbandry areas that rely on natural pasture grazing) are completely buried in snow. At these times, livestock are unable to find grassland and other food sources, often suffering from weight loss or death [4]. In the spring of 2019, frequent snowfall and extremely low temperatures in the TRHR caused part of the grassland to be covered with snow and ice for more than 40 days, which was a longer period than normal, freezing and starving a large quantity of cattle and sheep and affecting the income of local herdsmen and grassland animal husbandry [5].

Total snow accumulation is the decisive factor in snow disasters. Data on snow accumulation is acquired by monitoring ground meteorological stations [6], snow cover surveys, and remote sensing monitoring [7]. Compared to the shortcomings of the first two methods (e.g., with continuous and spatial representation), remote sensing monitoring methods provide wider spatial-temporal information, with an increasing number of researchers using MODIS [8-13], AMSR-E [14-16], and SSM/I [17-20]. Satellite sensors can detect snow accumulations, and ample research has been conducted to identify the gravity and extent of snow-stricken areas. Research shows that MODIS data can identify snow pixels more effectively. Combining MODIS with AMSR-E and SSM/I data can improve the ability to identify the snow covered area or snowpack properties. The formation of snow disasters is related to many factors, such as natural hazard factors, which include snow depth, snow density, snow duration, and grassland conditions, and anthropogenic factors, including livestock supplement feeding conditions and productivity levels [21-26].

In the Qinghai-Tibet Plateau, Zhu et al. [19] used SSM/I daylight temperature data from October to March in 1995-1996, 2000-2001, and 2005-2006. They measured snow depth data from 79 meteorological stations and retrieved the distribution of snow cover and snow depth in the eastern part of the Qinghai-Tibet Plateau. Their results show that during all three snow-covered seasons, snow-covered areas increased and reached their maximum in December and January before decreasing. The snow depth in each snow season was mainly $<5 \mathrm{~cm}$. Snow depths of $5 \sim 10 \mathrm{~cm}$ were mainly distributed in the Yushu and Guoluo located in TRHR (Figure 1). Li et al. [14] used the MODIS and AMSR-E data to monitor the snow cover of the six large pastoral areas in China from October 1, 2008 to March 31, 2009. Their results show that the Yushu in southern Qinghai and the Qinghai Lake grassland were regions with large fluctuations in snow cover. Snowfall forecasting should be done to help herders adjust production. The above research provided theoretical support for accurate assessments of the impact of snow disasters on livestock production in local grasslands and for developing defense measures.

However, research on the impact of snow disasters on animal husbandry production has paid little attention to the spatial distribution of areas at risk for snow disasters. Previous research tends to focus on the analysis of pre-snow disaster factors, and rarely on quantitative studies of the comprehensive disaster resistance capability in pastoral areas. It is impossible to accurately reflect the spatial differences in disaster prevention and resistance in various places, and it is not convenient for management departments to accurately and horizontally evaluate the extent of the impact of snow disasters on local animal husbandry. Moreover, a snow disaster like the one that occurred in the spring of 2019 is highly infrequent in the historical record. Its extent remains unclear, as do the differences in the comprehensive resistance among counties in TRHR.

In view of the above problems, we used satellite remote sensing technology to monitor the dynamic snow cover and snow depth in the TRHR during the spring of 2019. Further, we evaluated the spatial extent and degree of damage to grassland animal husbandry as a result of the snow disaster. The number of livestock affected by moderate snowfall to severe snow disasters was also evaluated. The proportion of livestock killed by the snow disaster (converted to standard sheep units (SUs)) to the estimated number of livestock affected by moderate, serious, and severe snow disasters (Table 1) was assessed. We determined the severity and spatial differences of grassland animal husbandry and the comprehensive resistance of each county under the combined effects of natural and anthropogenic factors. Finally, in response to the problems caused by the snow disaster to 
animal husbandry, countermeasures are proposed to mitigate the impact of snow disaster, providing a scientific basis for post-disaster recovery.

\section{Materials and Methods}

\subsection{Profile of Research Area}

The TRHR is located in the southern part of Qinghai Province, with an area of $363,000 \mathrm{~km}^{2}$, accounting for $50.3 \%$ of the total land area of Qinghai Province. Its administrative regions include Maduo, Malang, Dari, Gande, Jiuzhi, Banma, Zhiduo, Zaduo, Zhiduo, Qumalai, Nangqian, Yushu, Xinghai, Tongde, Zeku, Henan, and Tanggula (Figure 1). The TRHR is dominated by glaciers, periglaciers, mountains, highland plains, and hilly landforms. The elevation is between $2600 \mathrm{~m}$ and $6584 \mathrm{~m}$, and the topography is higher in the west and lower in the east. The TRHR has a grassland area of $271,000 \mathrm{~km}^{2}$, accounting for $69.70 \%$ of the total area. It also has a desert area of 5.8 million $\mathrm{km}^{2}$, accounting for $14.80 \%$ of the total area, and a water body and wetland area of 1.60 million $\mathrm{km}^{2}$, accounting for $4.20 \%$ of the total area. The grassland categories are sequenced from alpine meadows, warm grasslands, alpine grasslands, and alpine deserts from southeast to northwest, with its productivity decreasing accordingly $[27,28]$. The TRHR is located in an alpine zone on the northeastern edge of the Qinghai-Tibet Plateau. Due to the unique geographical environment and climatic conditions of the plateau, the frequent occurrence of snow disasters in winter and spring has a serious impact on local livestock production. Snow disasters were reported 756 times by 50 meteorological stations in Qinghai Province from 1961 to 2017: 486 mild disasters, 169 moderate disasters, 77 serious disasters, and 24 severe disasters [4].

Based on the changes in the number of snow disasters at various levels in the past 57 years, mild and serious disasters have increased slightly, whereas moderate and severe disasters have decreased. Though snow disasters occurred rarely in Qinghai Province over the past two decades, snow disasters remain likely in the TRHR, as it is growing obviously warmer and more humid in this region as a result of global warming.

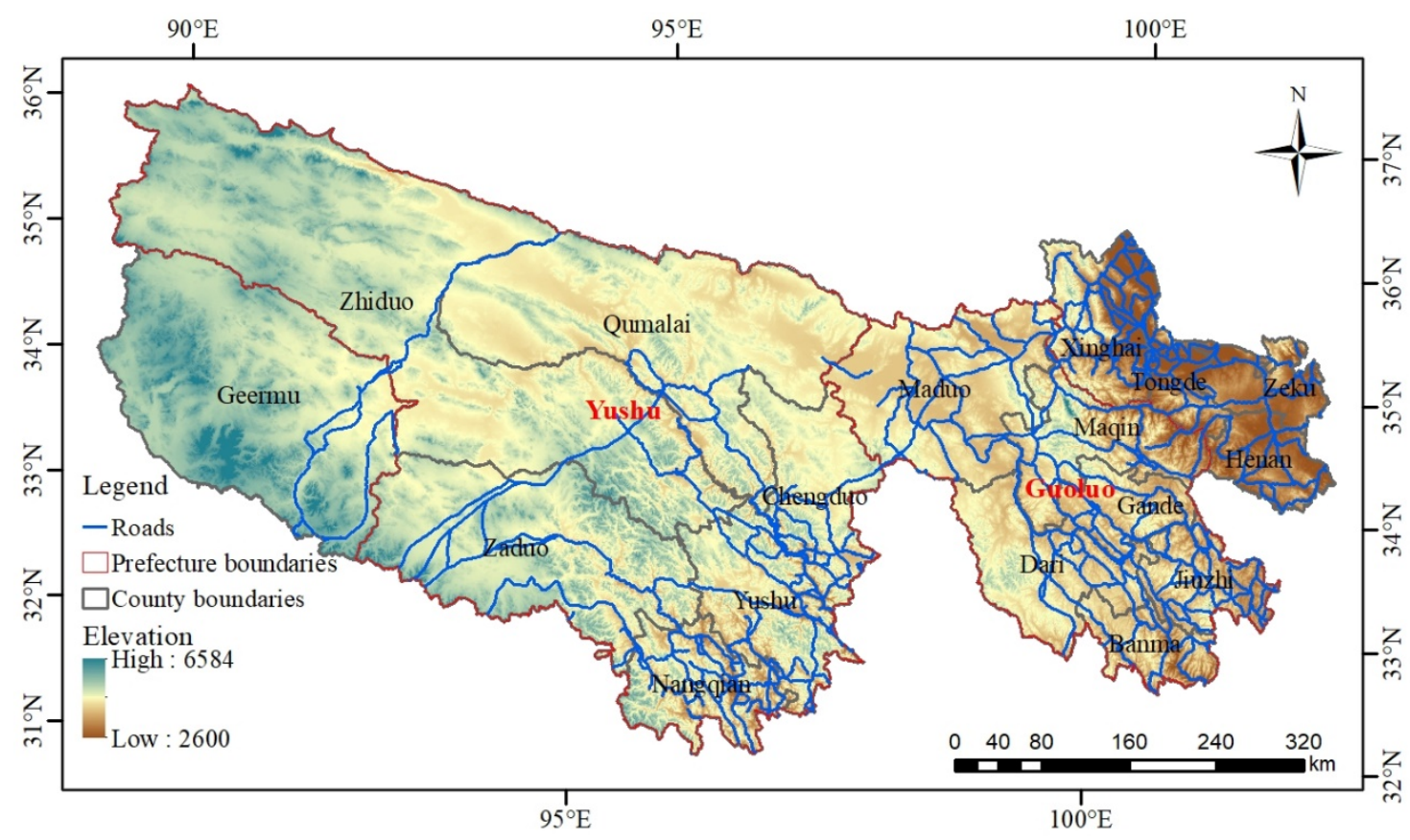

Figure 1. Digital elevation model of the Three-River Headwaters Region (TRHR). 


\subsection{Grassland Animal Husbandry Basic Data}

A grassland type and winter grassland spatial distribution map of the TRHR (Figure 2) was obtained from the TRHR Research Group at the Institute of Geographic Sciences and Natural Resources Research (CAS (IGSNRR)) based on national 1:1,000,000 grassland resource maps that mainly include attribute information, such as grassland types and grades. The data are provided by the authoritative department, so the data error will be $5 \%$ by the error theory. Due to early and frequent changes to the winter grassland boundary, we used a digital elevation model and land-use and land-cover change (LUCC) data from 2012 to correct it partially in places with low terrain, high grass canopy, and winter grazing. The LUCC data were obtained by the TRHR Research Group and was based on Landsat TM/ETM and HJ remote sensing images. Livestock reserves and the number of livestock deaths from the snow disaster were provided by the Qinghai Provincial Grassland Terminal.

The grass height of winter grasslands was determined by expert knowledge and from a spatial distribution map $(1: 1,000,000)$ of grassland types. The expert knowledge involved measurements conducted by the expert of Qinghai Provincial Station of Grassland from 2015 to 2017. First, based on the principle that grass is shorter in the winter than in the summer, combined with professional consultation with grassland scientists and grassland management personnel, the winter grass height in alpine meadows, alpine grasslands, and warm grasslands was determined to be $10 \mathrm{~cm}, 15 \mathrm{~cm}$, and $20 \mathrm{~cm}$, respectively.

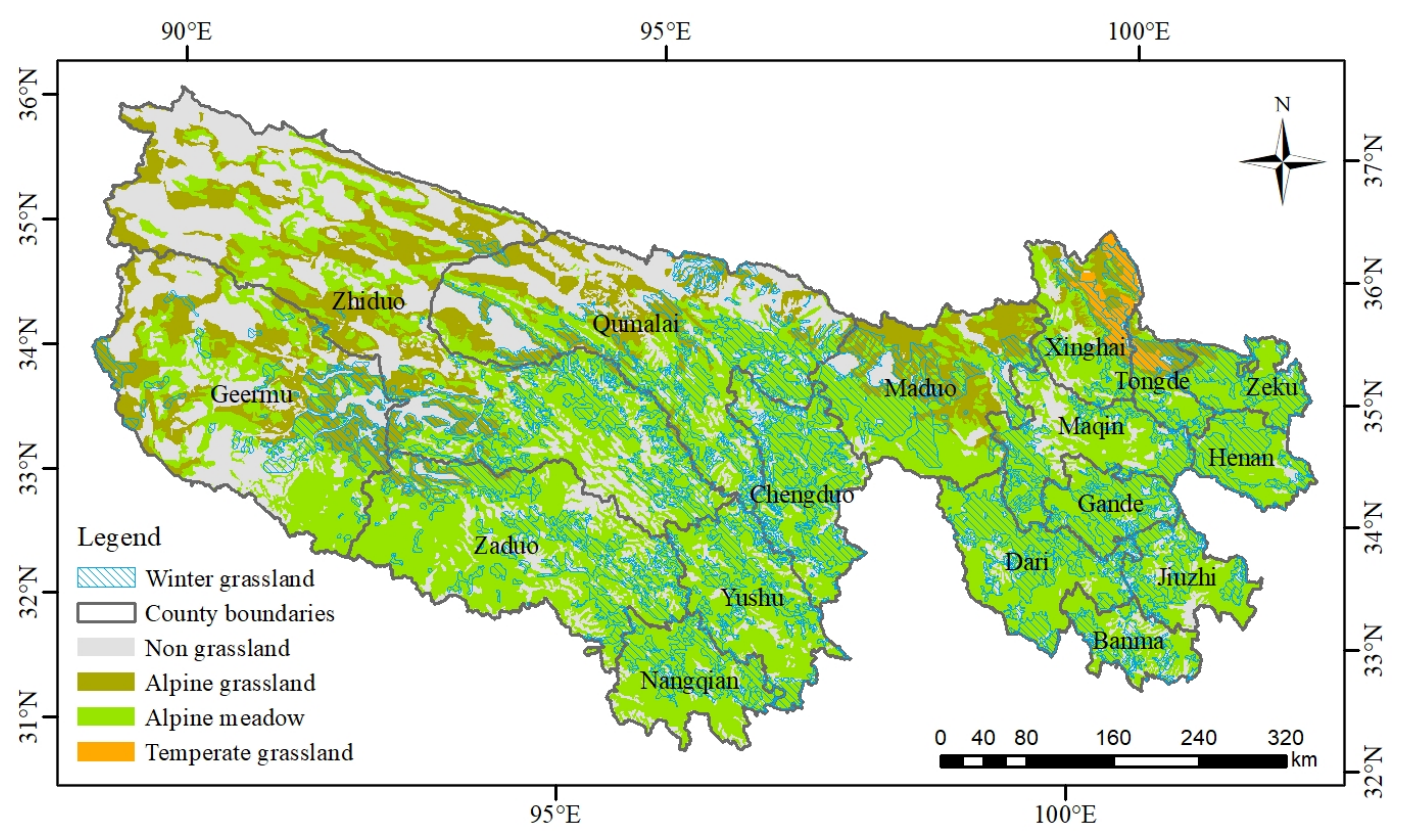

Figure 2. Spatial distribution of grass types and winter grassland boundaries in the TRHR.

\subsection{Snow Data and Snow Disaster Grading in Pastoral Areas}

Information regarding the snow cover and snow depth on 21 February, 27 February, and 02 March 2019 was obtained from the Institute of Meteorological Sciences, based on MODIS snow product data, passive microwave SSM/I brightness temperatures, and daily snow depth data from the Qinghai Provincial Ground Meteorological Station [29]. The MODIS snow product data comes from the MOD10A1 daily snow product provided by the US EOS/MODIS data center (https://modis.gsfc.nasa. gov) and the MOD10A2 eight-day synthetic snow product, both of which have a resolution of $500 \mathrm{~m}$ and equal-area sinusoidal projection. The normalized difference snow index (NDSI) was calculated based on the MODIS snow product to determine the snow area. The SSM/I brightness temperature data were derived from the National Environmental Satellite (Data and Information Service, NESDIS). 
The projection method was an EASE-Grid Global Cylindrical Equal Area projection with a spatial resolution of $25 \mathrm{~km}$ and temporal resolution of 1 day.

The number of snow-covered days was calculated using the snow cover and snow depth data. If a pixel indicated that the area it represented was covered by snow on both February 21 and March 2, that area had $\geq 10$ snow-covered days. If a pixel indicated snow cover on February 21 and 27, but not on March 2, there were $\geq 7$ snow- covered days. Otherwise, there were $<7$ snow-covered days.

According to the national standard for snow disasters [30], snow disasters in pastoral areas are classified into four grades-mild, moderate, serious, and severe-based on the depth of snow, the number of snow-covered days, and the grass height of winter grassland.

Table 1. Grade of pastoral area snow disaster [4].

\begin{tabular}{ccc}
\hline \multirow{2}{*}{ Snow Disaster Grades } & \multicolumn{2}{c}{ Snow State } \\
\cline { 2 - 3 } & Degree of Buried Graze by Snow & Continuous Days of Perpetual Snow (day) \\
\hline \multirow{2}{*}{ Mild disaster } & $0.30 \sim 0.40$ & $\geq 10$ \\
& $0.41 \sim 0.50$ & $\geq 7$ \\
\hline \multirow{2}{*}{ Moderate disaster } & $0.41 \sim 0.50$ & $\geq 10$ \\
& $0.51 \sim 0.70$ & $\geq 7$ \\
\hline \multirow{2}{*}{ Serious disaster } & $0.51 \sim 0.70$ & $\geq 7$ \\
\hline \multirow{2}{*}{ Severe disaster } & $0.71 \sim 0.90$ & $\geq 10$ \\
& $0.71 \sim 0.90$ & $\geq 7$ \\
\hline
\end{tabular}

\subsection{Comprehensive Disaster Resistance Capability Assessment Model}

The following steps were undertaken to estimate the number of livestock affected by the spring 2019 snow disaster. First, the county boundary, township boundary, and winter grassland were taken as input data using ArcGIS's union method to obtain the winter grassland of each administrative region. The winter grassland is the grazing land of all livestock in each county in the winter and spring seasons. Second, the livestock density of the winter pasture in each administrative region was obtained by dividing the number of livestock by the winter grassland area.

Third, spatial statistics were applied using the spatial distribution map of winter grassland and the grades of snow disasters in the TRHR in the spring of 2019. Consequently, we determined whether the respective winter grasslands areas in each administrative region suffered from mild, moderate, serious, or severe snow disasters. Finally, we multiplied the snow disasters area by the density of livestock in each administrative region to obtain the number of livestock affected by each grade of snow disaster in each administrative region. According to the Standards for the Rational Carrying Capacity of Natural Grassland in Qinghai Province, the conversion of sheep units (SUs) can be used to obtain the number of SUs affected by each grade of snow disaster in each administrative region. A standard sheep unit indicates one adult female sheep weighing 50 kilograms while feeding a lamb under half a year old that consumes 1.38 kilograms of standard hay per day, or the equivalent of other livestock.

$$
C_{j k}=S_{j} \times N_{k} / A
$$

where $C_{j k}$ is the number of SUs of the $k$ th species affected by the $j$ th grade of a snow disaster in a certain region; $S_{j}$ is the area of the winter grassland covered by the $j$ th grade of a snow disaster in a certain region; $N_{k}$ is the number of SUs of the $k$ th type of livestock in the winter grassland of an administrative region; $A$ is the winter grassland area of an administrative region; $j=1,2,3$, or 4 , respectively, representing a mild, moderate, serious, and severe snow disaster; and the upper limit of $k$ is the total number of livestock types.

This study assumes that mild snow disasters cause few livestock deaths. Thus, the number of livestock deaths reported by counties was considered to be the number of livestock killed exclusively by moderate, serious, and severe snow disasters. Our proposed index, the Comprehensive Disaster 
Resistance Capability Index (CDRCI), is the ratio of the number of livestock deaths to the number of SUs affected by moderate, serious, and severe snow disasters. The larger the index, the weaker the capacity for comprehensive disaster resistance. Likewise, the smaller the index, the stronger the capacity for disaster resistance $(<5 \%$, strong; $5 \% \sim 10 \%$, medium; $10 \% \sim 20 \%$, weak; and $>20 \%$, very weak). The CDRCI comprehensively reflects local conditions such as temperature, precipitation, topography, landform, and vegetation conditions, as well as the status of grassland animal husbandry infrastructure construction, such as winter forage reserves, greenhouses, and roads, and it characterizes the comprehensive disaster resistance capability of the local grassland livestock industry.

Rather than indicating livestock mortality, the CDRCI expresses a ratio between livestock deaths and livestock affected by moderate to severe snow disasters, rather than the total livestock. The CDRCI represents the comprehensive disaster resistance capability of grassland animal husbandry, enabling pastoral managers to quickly identify seriously stricken areas and ascertain the potential factors of the snow disaster, especially human-related factors. In this way, managers can produce constructive and concrete countermeasures to snow disasters, and they can provide better advice on snow disaster preparation and resistance.

It is more difficult to acquire the CDRCI than to derive figures on livestock mortality. The acquisition of the CDRCI requires coordinated action by the relevant departments of meteorology, animal husbandry, forestry, grasslands, and natural resources. Further, it uses an array of methods, such as remote sensing, ground surveillance, statistics, and investigation for precise acquisitions of relevant data on snow accumulations, grasslands, livestock, and the fundamental facilities of animal husbandry. As such, it is an objective assessment of the conditions of a snow disaster, allowing for fast response times.

The CDRCI for a region is defined as follows:

$$
I=\sum_{k=1}^{m} Z_{k} / \sum_{j=2}^{n} \sum_{k=1}^{m} N_{j k}
$$

where $I$ is the CDRCI; $Z_{k}$ is the number of livestock deaths for the $k$ th species of livestock in a certain administrative region; $N_{j k}$ is the number of SUs for $k$ th species affected by moderate to severe snow disasters in an administrative region, among which $j=2,3$, and 4 represent moderate, serious, and severe snow disasters, respectively; and $m$ is the total number of livestock species.

\section{Results and Analysis}

\subsection{Snow Distribution and Characteristics}

According to the EOS/MODIS satellite remote sensing for 21 February, 27 February, and 02 March 2019, snow-covered areas were mainly in the central and eastern parts of the TRHR, distributed in the southeast of Yushu and the western and southwestern parts of Guoluo. The local distribution is patchy, with an uneven distribution, resulting in spatial differences in the snow disaster situation.

During the study period, the total snow-covered area in the TRHR continued to increase, from $12,240 \mathrm{~km}^{2}$ on February 21 to $164,600 \mathrm{~km}^{2}$ on February 27, reaching 21.20 million km² on March 02. This represents $34.25 \%, 46.03 \%$, and $59.26 \%$ of the total area of the TRHR, respectively.

Among the 16 counties in the TRHR, 10 counties were such that more than $50 \%$ of the land was snow-covered. Of these, five counties had over $90 \%$ of land covered in snow, namely, Nangqian, Yushu, Maduo, Malang, and Gande. The percentage of snow cover was between $50.10 \%$ and $88.90 \%$ in Henan, Daji, Jiuzhi, Chengduo, and Zaduo (Figure 3). During the study period, the proportion of snow cover in TRHR counties increased to varying degrees. Among them, the proportion of snow cover in Jiuzhi County increased the most, accounting for $60.48 \%$, followed by NangQian, Henan, Yushu, and Chengduo, with 51.88\%, 45.59\%, 36.62\%, and 35.73\%, respectively. Large snow-covered areas inevitably affect local livestock production. 


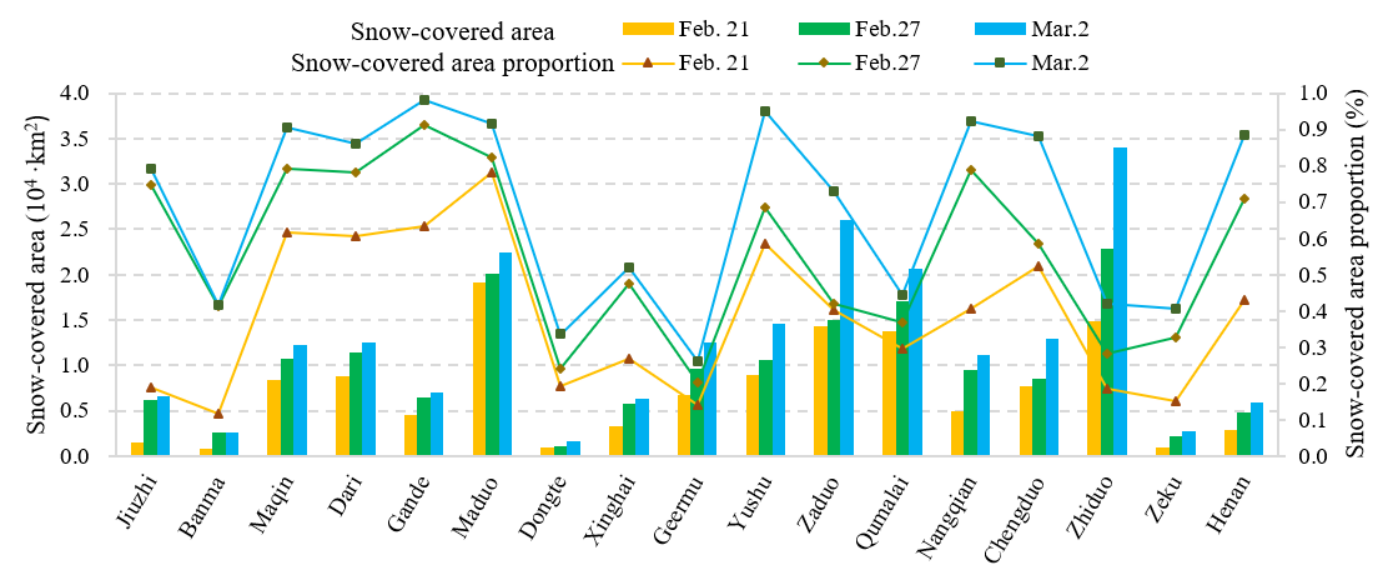

Figure 3. Snow-covered areas and proportion in TRHR counties on 21 and 27 February as well as 02 March 2019.

The depth of snow directly determines the extent to which pasture land is buried. As such, it is a key factor in assessing the extent of damage in pastoral areas. This is especially true for the TRHR in pastoral areas where winter grasses are short. During the study period, the average snow depth in the TRHR continued to increase. The average snow depths on 21 February, 27 February, and 02 March 2019 were $3.33 \mathrm{~cm}, 3.99 \mathrm{~cm}$, and $4.04 \mathrm{~cm}$, respectively. The snow depth varied greatly from place to place. In Banma, Jiuzhi, Tongde, Zeku, and other places, it was relatively low of less than $2 \mathrm{~cm}$, whereas in parts of Maduo, Chengduo, Yushu, Nangqian, Maqin, Dari, and Gande it was generally around $10 \mathrm{~cm}$. Because the grassland type in these counties is dominated by alpine meadows with grasses that are short in the winter, the snow made it especially difficult for cattle and sheep to forage.

According to the Meteorological Disaster Standard of the Qinghai Provincial Technical Supervision Bureau, the grades of pastoral-area snow disasters, and the winter grassland canopy height in the TRHR, we classified the snow depth data in TRHR on 21 February, 27 February, and 02 March 2019 into five grades: $0 \sim 2 \mathrm{~cm}, 2 \sim 5 \mathrm{~cm}, 5 \sim 10 \mathrm{~cm}, 10 \sim 15 \mathrm{~cm}$, and $>15 \mathrm{~cm}[30,31]$.

On all three days, the snow depth of the whole area was mainly below $10 \mathrm{~cm}$, with $120,800 \mathrm{~km}^{2}$, $159,300 \mathrm{~km}^{2}$, and 209,600 km² of snow-covered areas on 21 February, 27 February, and 02 March 2019 , respectively. This in proportion to the total area was $33.78 \%, 44.55 \%$ and $58.6 \%$, respectively. Accumulations of $5 \sim 10 \mathrm{~cm}$ and 10 15 cm were mainly distributed in the areas of Yushu, the southern part of the Nangqin, the majority of Maduo, the western part of Maqin, the western part of Dari, and the northwest of Gande.

Areas with snow depths of $0 \sim 2 \mathrm{~cm}, 2 \sim 5 \mathrm{~cm}$, and $5 \sim 10 \mathrm{~cm}$ continued to increase on these days. Because of the snowfall and low temperatures in late February, the local temperature rose above the freezing point in March. The coverage area of the 10 15 cm grade on 21 February, 27 February, and 02 March 2019 changed significantly from "less to more, then more to less" at $6263 \mathrm{~km}^{2}, 20,972 \mathrm{~km}^{2}$, and $8648 \mathrm{~km}^{2}$, respectively (Figure 4), while the coverage area of the $>15 \mathrm{~cm}$ grade appeared as "more to less, then less to more" at $424 \mathrm{~km}^{2}, 169 \mathrm{~km}^{2}$, and $239 \mathrm{~km}^{2}$, respectively.

Among the 16 counties in the TRHR, seven counties were such that more than $40 \%$ of the land had snow that was 5 10 cm deep (viz., Maqin, Gande, Dari, Maduo, Yushu, Chengduo, and Nangqian). In Yushu, Maduo, and Nangqian, $5 \sim 10 \mathrm{~cm}$ of snow covered $70.15 \%, 57.76 \%$, and $55.66 \%$ of the land, respectively.

Snow that was 2 5 $\mathrm{cm}$ deep was mainly distributed in the central and eastern parts of Qumalai, the western part of Gande, and the eastern part of Maqin. Snow that was $2 \sim 5 \mathrm{~cm}$ deep covered Xiawu Town, Youyun Town in Maqin, and Huashixia Town in Madu, with $59.20 \%, 61.30 \%$, and $53.60 \%$, respectively.

From the end of February to the beginning of March 2019, snow-covered areas lasted more than 10 days in some areas of the TRHR, mainly in the central-eastern parts, such as the eastern part of Yushu and the western part of Guoluo. Areas with 7-10 days of snow cover were mainly distributed in 
the southern part of the Nangqin and the eastern part of the TRHR, including Banma, Jiuzhi, and parts of Gande and Henan. Areas with less than 7 days of snow cover were mainly distributed in the west and northeast of the TRHR, including Xinghai and Tongde. According to the spatial distribution map of snow-covered days, most of the Yushu and Guoluo had serious snow disasters.

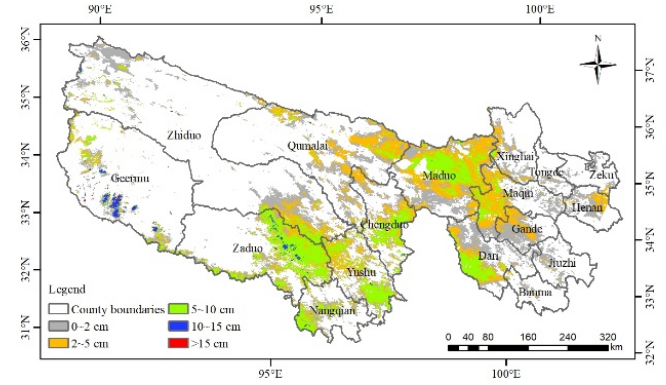

(a)

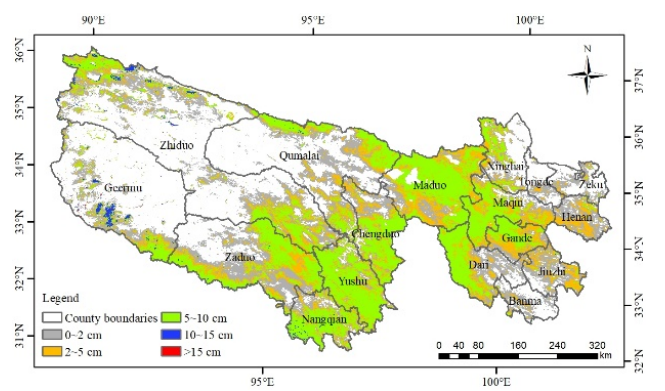

(c)

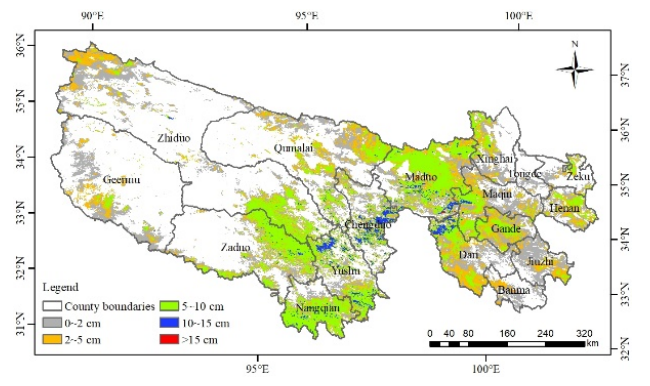

(b)

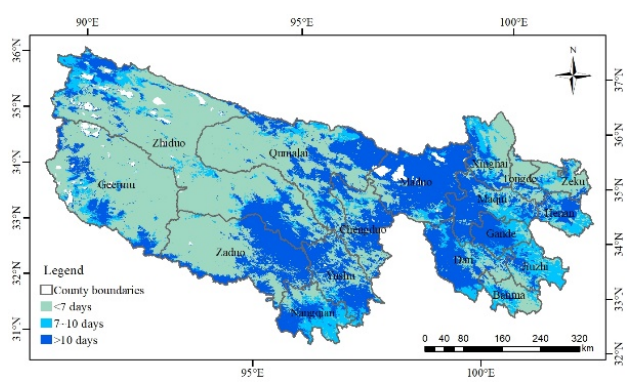

(d)

Figure 4. Spatial distribution of snow depth in the TRHR on 21 February (a), 27 February (b), and 2 March (c), 2019, and the number of snow-covered days (d).

\subsection{Snow Disaster Level and Spatial Difference in the Number of Affected Livestock}

The snow disaster classification method was used to calculate the snow disaster level distribution map of the TRHR, according to the snow depth, duration, and winter grassland height (Figure 5). The results show that serious snow disasters accounted for the largest area among the four grades of snow disasters, with a total area of $21,400 \mathrm{~km}^{2}$. This was followed by moderate, mild, and severe snow disasters, with an area of $16,200 \mathrm{~km}^{2}, 14,500 \mathrm{~km}^{2}$, and $12,800 \mathrm{~km}^{2}$, respectively. Severe snow disasters were mainly distributed in Maduo, Zaduo, Nangqian, Yushu, and Dari with an area of 0.31 million $\mathrm{km}^{2}$, 0.30 million $\mathrm{km}^{2}, 0.20$ million $\mathrm{km}^{2}, 0.15$ million $\mathrm{km}^{2}$, and 0.10 million $\mathrm{km}^{2}$, respectively. Serious snow disasters were mainly distributed in Maduo, Zaduo, Duduo, Nangqian, and Yushu with an area of 0.40 million $\mathrm{km}^{2}, 0.39$ million $\mathrm{km}^{2}, 0.22$ million $\mathrm{km}^{2}, 0.21$ million $\mathrm{km}^{2}$, and 0.20 million $\mathrm{km}^{2}$, respectively. Moderate snow disasters were mainly distributed in Maduo, Maqin, Qumalai, Yushu, and Zaduo, with an area of 0.26 million $\mathrm{km}^{2}, 0.23$ million $\mathrm{km}^{2}, 0.17$ million $\mathrm{km}^{2}, 0.15$ million $\mathrm{km}^{2}$, and 0.14 million $\mathrm{km}^{2}$, respectively. Mild snow disasters were mainly distributed in Qumalai, Maduo, Zhiduo, Maqin, and Dari, with an area of 0.21 million $\mathrm{km}^{2}, 0.20$ million $\mathrm{km}^{2}, 0.13$ million $\mathrm{km}^{2}$, 0.12 million $\mathrm{km}^{2}$, and 0.10 million $\mathrm{km}^{2}$, respectively. Moderate to severe snow disasters were mainly distributed in Maduo, Zaduo, Nangqian, Yushu, and Dari, in the middle of the TRHR, with an area of 0.97 million $\mathrm{km}^{2}, 0.85 \mathrm{~km}^{2}, 0.52$ million $\mathrm{km}^{2}, 0.51$ million $\mathrm{km}^{2}$, and 0.39 million $\mathrm{km}^{2}$, respectively.

According to the snow disaster level distribution map and the livestock density of the counties in the TRHR, we calculated the number of SUs affected by the four grades of snow disasters in each administrative region (Figure 5). Indeed, the central and eastern areas of the TRHR, where the snow disaster occurred in concentrated areas, are important grasslands for animal husbandry in Qinghai.

The number of livestock affected by moderate to severe snow disasters in the TRHR was about 2.31 million SUs, comprising 525,000 heads of yak ( 1 yak $\approx 4$ SUs) and 213,000 sheep, and accounting for $78.30 \%$ of the total number of SUs affected by snow disasters (including mild snow disasters) in the 
TRHR. There were about 1.54 million SUs specifically affected by severe snow disasters, including 355,000 heads of yak and 12,200 heads of sheep, accounting for $52.10 \%$ of the total number of SUs affected in the TRHR. The number of livestock in eight counties-namely, Yushu, Zhiduo, Zaduo, Nangqian, Maduo, Malang, Dari, and Gande - which were more seriously affected by snow disasters, was about $7,738,800 \mathrm{SU}$, accounting for $43.60 \%$ of the total number of livestock in the TRHR. In the above eight counties, the number of livestock affected by moderate to severe snow disasters was about $2,074,000$ SUs, accounting for $89.70 \%$ of the total number of SUs affected by moderate to severe snow disasters in the TRHR. There were about 14.45 million SUs affected by serious and severe snow disasters, accounting for $93.80 \%$ of the total number of SUs affected by serious and severe snow disasters.

Among the various regions in the TRHR, Yushu Prefecture was the most affected. The number of livestock affected by moderate to severe snow disasters was about 1.65 million SUs, including about 390,000 yaks and 76,000 Tibetan sheep, accounting for about $85.60 \%$ of the total number of SUs affected by snow disasters in Yushu Prefecture. The number of livestock affected by serious and severe snow disasters was about 1.24 million SUs, including about 295,000 heads of yak and about 55,000 sheep, accounting for about $64 \%$ of the total number of SUs affected by snow disasters in Yushu Prefecture. The number of livestock affected by moderate to severe snow disasters in Guoluo Prefecture was about 542,200 SUs, including about 112,000 heads of yak and about 95,000 heads of Tibetan sheep and accounting for about $70 \%$ of the total number of SUs affected by snow disasters in Guoluo Prefecture. The number of livestock affected by serious and severe snow disasters was about 263,000 SUs (53,000 yaks and 51,000 sheep), accounting for $33.80 \%$ of the total number of SUs in Guoluo Prefecture.

Among the counties, from the perspective of the number of livestock affected by snow disasters, Nangqian, Zaduo, Yushu, Maqin, and Duoduo were the most seriously affected. In these counties, yaks affected by moderate to severe snow disasters numbered 155,463, 93,801, 77,594, 48,228, and 44,399, respectively, and Tibetan sheep numbered 13,499, 22,571, 11,918, 52,526, and 12,615, respectively. From the perspective of the proportion of livestock affected by snow disasters, Maduo, Nangqian, Maqin, Yushu, and Dudu were the most seriously affected counties, where the number of livestock affected by moderate to severe snow disasters respectively accounted for $41.20 \%, 39.60 \%, 31.90 \%$, $24.17 \%$, and $22.30 \%$ of the total number of SUs of each county. Tongde, Banma, Jiuzhi, and Zhiduo were the least affected counties. Livestock affected by moderate to severe snow disasters there accounted for $0.08 \%, 0.24 \%, 1.10 \%$, and $1.60 \%$ of the total number of livestock, respectively.

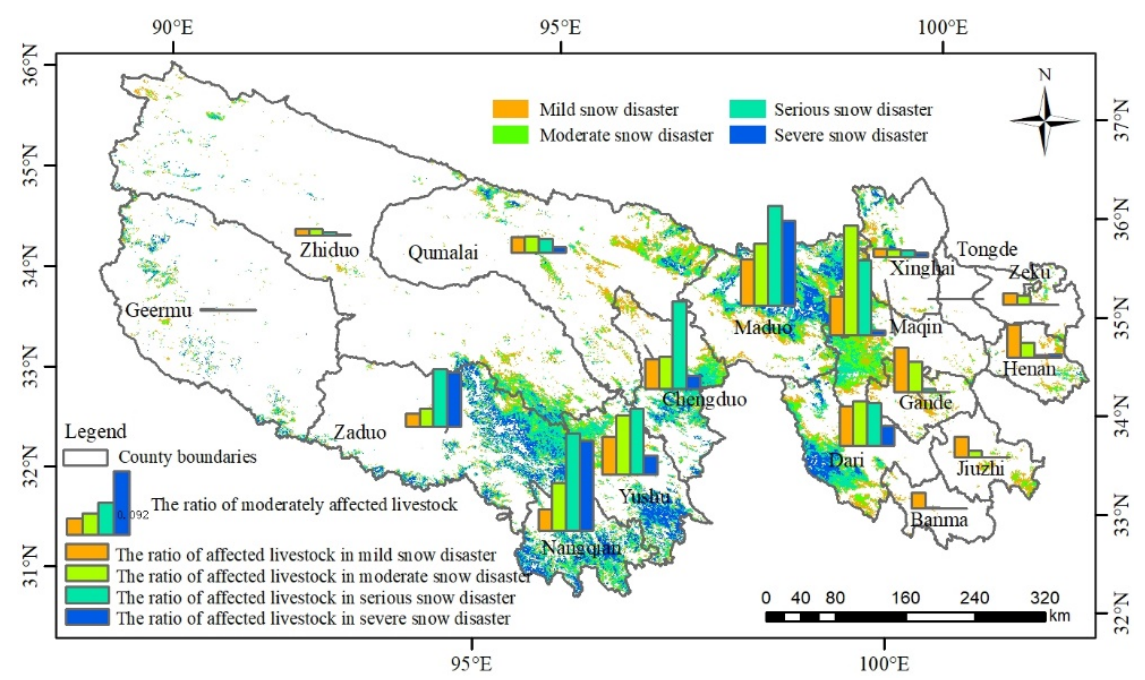

Figure 5. Spatial statistical map of snow disaster grades and the ratio of affected livestock in TRHR counties in spring, 2019. 
The main natural factors that led to severe snow disasters in the TRHR were important to consider. First, large-scale persistent and heavy snowfall occurred in the snow disaster area. Since December 2018, most of the TRHR had experienced regular snowfall and low temperature below $0{ }^{\circ} \mathrm{C}$. Cold weather occurred in Qumalai, Maduo, Zaduo, and other places in the core area of the TRHR. Heavy snowfall occurred persistently in the snow disaster area, with accumulations of more than $40 \mathrm{~cm}$ in some areas.

Second, there were low temperatures in the snow disaster area throughout this period. As such, the snow did not melt. Due to the influence of cold air and the snowfall, there was protracted cold weather in the TRHR. The maximum temperature (high temperature) remained below $0{ }^{\circ} \mathrm{C}$ for about 3 months. The temperature in the snow disaster area was generally low, the snow melted slowly, and snow increased subsequently. There were more than 10 days of snow-covered in most areas of Yushu and Guolu (Figure 1), for example.

Third, because the grassland covered by snow was mostly alpine meadow vegetation, the grass was relatively short and covered by snow, making it difficult for cattle and sheep to feed.

\subsection{Spatial Differences in Comprehensived Disaster Resistance Capability}

Yushu and Guoluo Prefectures were the key areas for this snow disaster. Livestock killed in these two prefectures numbered 108,900 SUs and 47,600 SUs, respectively. At the county level, Zaduo had the largest number of dead livestock due to snow disasters, with about 35,500 SUs, followed by Zaduo, Yushu, Gande, Maduo, and Zhiduo at 26,800 SUs, 24,000 SUs, 23,700 SUs, 15,000 SUs, and 10,500 SUs, respectively. The number of dead livestock due to snow disasters was relatively smaller in the other counties. Each had fewer than 10,000 SUs die.

There are large differences in the CDRCIs of grassland animal husbandry in the counties of Yushu Prefecture and Guoluo Prefecture (Table 2). The CDRCI of Zhiduo is higher than that of the other counties, at $51.20 \%$. This is followed by $14.10 \%$ in Chengduo, $11.50 \%$ in Qumalai, $8.90 \%$ in Zaduo, $7.40 \%$ in Yushu, and only $0.38 \%$ in Yuqian. The CDRCI of Gande is higher than that of the other counties In Guoluo Prefecture, at $48.40 \%$, followed by $13.30 \%$ in Maduo, 3.70\% in Dari, $1.70 \%$ in Maqin, and $1.30 \%$ in Jiuzhi. Counties with strong comprehensive disaster resistance capability included Nangqian, Jiuzhi, Maqin, and Dari. Those with moderate comprehensive disaster resistance capability included Yushu, and Zaduo. Counties with weak comprehensive disaster resistance capability included Duo, Qumalai, and Maduo. Finally, the counties with extremely weak comprehensive disaster resistance capability were Zhiduo and Gande.

Table 2. CDRCI in Yushu and Guoluo counties for the 2019 spring snow disasters.

\begin{tabular}{|c|c|c|c|c|c|c|c|c|}
\hline \multirow{2}{*}{ State } & \multirow{2}{*}{ County } & \multicolumn{2}{|c|}{$\begin{array}{c}\text { Number of Livestock } \\
\text { Deaths by Snow Disasters }\end{array}$} & \multicolumn{3}{|c|}{$\begin{array}{l}\text { Number of Livestock Deaths from } \\
\text { Moderate to Severe Snow Disasters }\end{array}$} & \multirow{2}{*}{$\begin{array}{l}\text { Ratio of the Number of Livestock Deaths } \\
\text { to the Number of Those Affected by } \\
\text { Moderate to Severe Snow Disasters (\%) }\end{array}$} & \multirow{2}{*}{$\mathrm{CDRCI}^{1}$} \\
\hline & & Count & Sheep Unit & Cattle & Sheep & Sheep Unit & & \\
\hline \multirow{7}{*}{ Yushu } & Yushu & 6100 & 23,953 & 77,594 & 11,918 & 322,294 & 7.43 & \multirow{7}{*}{$\begin{array}{c}\text { moderate } \\
\text { Weak } \\
\text { Strong } \\
\text { moderate } \\
\text { extremely } \\
\text { weak } \\
\text { Weak } \\
\text { moderate }\end{array}$} \\
\hline & Chengdu & 7200 & 26,841 & 44,399 & 12,615 & 190,211 & 14.11 & \\
\hline & Nangqian & 600 & 2400 & 155,463 & 13,499 & 635,351 & 0.38 & \\
\hline & Zaduo & 9400 & 35,488 & 93,801 & 22,571 & 397,775 & 8.92 & \\
\hline & Zhiduo & 3000 & 10,500 & 4498 & 2513 & 20,505 & 51.21 & \\
\hline & Qumalai & 3600 & 9675 & 17,661 & 13,351 & 83,995 & 11.52 & \\
\hline & Total & 29,900 & 108,857 & 393,416 & 76,467 & $1,650,131$ & 6.60 & \\
\hline \multirow{6}{*}{ Guoluo } & Maduo & 5100 & 14,977 & 21,404 & 26,951 & 112,567 & 13.30 & \multirow{6}{*}{$\begin{array}{c}\text { Weak } \\
\text { extremely } \\
\text { weak } \\
\text { Strong } \\
\text { Strong } \\
\text { Strong } \\
\text { moderate }\end{array}$} \\
\hline & Gande & 6200 & 23,735 & 11,853 & 1650 & 49,062 & 48.38 & \\
\hline & Dari & 1300 & 4450 & 26,749 & 14,595 & 121,591 & 3.66 & \\
\hline & Maqin & 1400 & 4248 & 48,228 & 52,526 & 245,438 & 1.73 & \\
\hline & Jiuzhi & 41 & 161 & 3041 & 183 & 12,347 & 1.30 & \\
\hline & Total & 14,041 & 47,571 & 111,275 & 95,905 & 541,005 & 8.79 & \\
\hline
\end{tabular}

${ }^{1}$ Note: the CDRCI is estimated by the ratio of damaged livestock SUs to moderately to severely affected ones, $<5 \%$, strong; $5 \% \sim 10 \%$, moderate; $10 \% \sim 20 \%$, weak; $>20 \%$, extremely weak.

This study shows that the absolute number of affected livestock cannot accurately reflect spatial differences in disaster prevention and resistance. The proposed CDRCI, by contrast, accurately assesses 
the impact and extent of snow disasters in the TRHR. For example, livestock killed in Yushu Prefecture and Guoluo Prefecture numbered 108,900 SUs and 47,600 SUs, respectively. Livestock affected by moderate to severe snowfall in Yushu Prefecture and Guoluo Prefecture totaled 1.45 million and 541,100 SUs respectively. The CDRCI of grassland animal husbandry in Yushu Prefecture and Guoluo Prefecture was $6.60 \%$ and $8.79 \%$, respectively.

From the perspective of the absolute number of affected livestock, the snow disaster situation in Yushu Prefecture was relatively pronounced. According to the CDRCI, however, the comprehensive disaster resistance capacity of grassland animal husbandry in the two Prefectures was moderate overall, and the CDRCI in Yushu Prefecture was slightly lower than in Guoluo, which is more in line with the actual situation.

\section{Discussion}

\subsection{Comprehensive Disaster Resistance Capability Analysis and Snow Disaster Response Policy Recommendations}

The formation of snow disasters is an unfavorable result of the combination of natural and human factors. It mainly includes two processes. First, the disaster-causing process includes the accumulation of snow and interference with animal husbandry production. The intensity of this disturbance can be reflected by the number of livestock affected by moderate to severe snow disasters. Second, the disaster-resistance process pertains to the reliance of animal husbandry production on natural and human factors for disaster-resistance in snowy weather. The intensity of the disaster-resistance ability can be reflected by the number of dead livestock due to disasters. In the disaster-causing process, the number of livestock affected by moderate to severe snow disasters is closely related to natural and human factors, such as the local snow-covered area, snow depth, snow-covered days, grass height, altitude, temperature, and livestock density. Natural factors are the main controlling factors of the disaster-causing process. This is consistent with the research results of the average risk distribution of snow disasters in Qinghai and the maximum snow depth, slope, and snow-covered days by Ma et al. [32]. During the disaster-resistance process, the number of dead livestock due to disasters is closely related to natural factors such as altitude, temperature, topography, and grass height, along with human factors, such as warm sheds, circle nests, stored forage, and artificial foraging areas. The main controlling factors vary from place to place, but natural factors are still a key factor in the disaster response process.

Snow disasters caused a certain loss to the grassland animal husbandry in the TRHR. The main reasons for the strong comprehensive disaster resistance capability in some areas are as follows.

First, the natural disaster conditions were relatively good. For example, the disaster in the Nangqian was relatively mild, because the with lower altitude and higher grass canopy were able to mitigate snow disaster. This is also related to the topography, vegetation, and temperature characteristics of the county. Cold-season pastureland in Nangqian is mostly distributed in the mountain valleys. Due to factors such as the occlusion of the mountains, the cold wind is relatively weak, and the temperature is relatively high compared to other areas. In addition, Nangqian has a certain number of mountain meadows, and the vegetation is taller and with more shrubs than other counties. These factors mitigate the hazards of snow disasters to a certain extent. Zhiduo has a relatively low comprehensive disaster resistance capability due to its relatively high altitude and relatively low temperatures. The reason why Gande has an extremely weak comprehensive disaster resistance capability is that the proportion of its snow-covered area was the highest in the TRHR, accounting for $91 \%$ of the total. This made livestock foraging very difficult.

Second, anthropogenic disaster measures were properly prepared. For a long time, artificial grass foraging, forage material processing, warm sheds, circle nests, and other grassland animal husbandry infrastructure have existed, and winter feed storage has been emphasized. There is a forage material emergency reserve system, and a good village road network to provide the most basic guarantees for disaster relief with significantly improved comprehensive disaster response capability. 
For example, in 2018, Yushu, Zaduo, Zhiduo, Yushu, Qumalai, and Nangqian respectively transported 1.40 million tons, 11,000 tons, 0.6 million tons, 0.50 million tons, 0.31 million tons, and 0.21 million tons of forage materials through village road networks. Dari, Nangqian, Maqin, Jiuzhi, Yushu, and Zaduo built artificial forage grassland areas extending $86,000 \mathrm{ha}, 23,333 \mathrm{ha}, 12,000 \mathrm{ha}, 16,666 \mathrm{ha}, 41,333 \mathrm{ha}$, and 36,666 ha, respectively. These measures effectively reduced the local disaster level and improved the comprehensive disaster resistance capability.

During the spring the situation of the disaster begins to stabilize because from February onwards the temperature rises to above $0^{\circ} \mathrm{C}$. However, the number of livestock deaths may increase due to factors such as livestock weight loss from snow disasters. Relevant departments need to actively respond and take effective measures. At the same time, there were some problems with the snow disaster response, such as insufficient meteorological observation capability, imperfect disaster emergency services, less grassland animal husbandry infrastructure and forage material, an unreasonable spatial layout, insufficient forage reserves, and small coverage of modern ecological animal husbandry. It is thus recommended that the relevant departments strengthen the capacity for snow disaster monitoring and early warnings, increase the construction of grassland animal husbandry infrastructure and stored forage material, and facilitate modernized and ecological animal husbandry in the TRHR. Further, a long-term mechanism for assessing the risk of snow disasters should be established, with comprehensive disaster response to ensure the healthy, stable, and sustainable development of animal husbandry in the TRHR.

\subsection{Uncertainty Analysis of Comprehensive Disaster Resistance Capability}

The accuracy of the CDRCI varies greatly depending on the accuracy, timeliness, and completeness of winter livestock data, the number of dead livestock due to snow disasters, and winter pasture boundary data. Due to the lack of recent winter livestock inventory data in the counties and the early boundary data of the TRHR winter grassland, the number of affected livestock and the CDRCI of grassland animal husbandry in each region are uncertain. The winter grassland boundary data of the TRHR used in this paper were based on previous data, and needed to be adjusted before the next snow disaster assessment. Although the boundary data were revised with respect to the influence of terrain, land-use type, and other factors, and were in accordance with local animal husbandry management department recommendations, the actual concentration of winter grazing areas for livestock remained inconsistent. This made the calculation results uncertain. The grassland height data used in this paper was obtained based on expert knowledge and a 1:1,000,000 spatial distribution map of grassland types, but the spatial resolution was coarse, and it failed to accurately reflect the spatial differences in grass height in the TRHR. More accurate monitoring of winter grass height, such as more ground observations, can thus improve snow disaster assessment work.

At the same time, the density of livestock in winter grasslands is not evenly distributed. Therefore, the estimation of the number of livestock affected by snow disasters is relatively small in the administrative area where snow-covered areas were relatively large, while the error in other areas is relatively large. The accuracy of the reported number of dead livestock due to snow disasters also directly affects the CDRCI. In order to reduce the uncertainty of the calculation results of the CDRCI, it is recommended that future research strengthen collected data with updated winter livestock inventories and clearer winter grassland boundaries, so as to improve the accuracy of CDRCI calculations of grassland animal husbandry in the research area.

\section{Conclusions}

Based on data from remote sensing, ground monitoring, and statistical surveys, this study analyzed the snow disaster situation in the TRHR in the winter and spring of 2019. Based on a snow disaster classification model of the pastoral area and the estimated number of affected livestock, we devised an index, called the CDRCI, to measure and evaluate the effect of snow disasters on livestock in the TRHR. Moderate to severe snow disasters in the spring of 2019 were mainly distributed in 
Maduo, Zaduo, Nangqian, Yushu, Dari, and other counties in the middle of the TRHR. The snow depth, snow-covered days, winter grass height, winter grassland elevation, and temperature were the main factors affecting these areas. The number of livestock affected by moderate to severe snow disasters in the TRHR was about 2.31 million SUs. The number of livestock affected by snow disasters varied greatly across counties, however. There were relatively more livestock affected by snow disasters in Nangqin, Zaduo, Yushu, Maqin, and Chengduo, and relatively fewer in Tongde, Banma, Jiuzhi, and Zhiduo. The comprehensive disaster resistance capability of grassland animal husbandry in Yushu Prefecture and Guoluo Prefecture was generally moderate, and slightly stronger in Yushu Prefecture than in Guoluo Prefecture. There were considerable differences in the CDRCIs of grassland animal husbandry in various counties, namely (in descending order) Nangqian, Jiuzhi, Maqin, Dari, Yushu, Zaduo, Chengduo, Qumalai, Zhiduo, and Gande. Natural factors such as topography, vegetation, and temperature, alongside snow disaster measures such as forage processing, warm sheds, circle nests, and other grassland animal husbandry infrastructure, were the main factors used to determine the comprehensive disaster resistance capability by providing food and shelter for livestock. We expect that the proposed CDRCI can be used to characterize and evaluate the comprehensive disaster resistance in various counties. The results can be used for rapid one-week assessments of the impact of snow disasters on grassland animal husbandry in the TRHR, providing technical support for the implementation of disaster prevention and resistance measures by animal husbandry management departments.

Author Contributions: All the authors contributed significantly to this study. Q.S., J.L., and J.F. proposed the idea. G.L. wrote the manuscript. J.L. and Q.S. designed the experiments. Q.S., G.L., X.L., and H.H. processed the data.

Funding: This research was funded by the National Natural Science Foundation of China (Grant No. 41571504), the CAS Strategic Leading Science and Technology Project Category A (Grant No. XDA23100203), and the National Key Research and Development Program of China (Grant No. 2017YFC0506501).

Acknowledgments: The authors are grateful to the editor and anonymous reviewers of this paper. Deputy director Chaoyuan Zhang of Qinghai Provincial Science and Technology Department and deputy director Fengxia Li of Qinghai Provincial Meteorological Bureau gave guidance; senior engineer Zhenying Yan of Qinghai Provincial Station of Grassland provided relevant statistics; professor Xinquan Zhao of Northwest Institute of Plateau Biology, Chinese Academy of Sciences, and senior engineer Bingrong Zhou of Qinghai Provincial Institute of Meteorological Sciences provided assistance; and Dapeng Liu of the Institute of Geographical Sciences and Natural Resources Research, CAS, participated in the calculations.

Conflicts of Interest: The authors declare no conflict of interest.

\section{References}

1. Shao, Q.; Fan, J. Monitoring and Evaluation of Ecological Benefits of Three-River Source Region Ecological Protection and Construction Project, 1st ed.; Science Press: Beijing, China, 2018; pp. 19-20.

2. Shao, Q.; Fan, J. Integrated Monitoring and Assessment of Ecosystem in Three-River Source Region, 1st ed.; Science Press: Beijing, China, 2012; p. 7.

3. Shao, Q.; Fan, J.; Liu, J.; Huang, L.; Cao, W.; Liu, L. Target-based Assessment on Effects of First-stage Ecological Conservation and Restoration Project in Three-river Source Region, China and Policy Recommendations. Bull. Chin. Acad. Sci. 2017, 32, 35-44.

4. Li, H.; Li, X.; Zhang, H. Research on snow disaster level indicators in pastoral areas in China. Qinghai Meteorol. 2006, 1, 24-29.

5. The Core Area of Three River Source Region Suffered Severe Snow Disaster. Available online: https: //baijiahao.baidu.com/s?id=1622082355301229207\&wfr=spider\&for=pc,2019-01-04/2019-03-01 (accessed on 8 January 2019).

6. Wu, J.; Zhu, G.; Zhou, Q. Investigation on the Snow Cover of Mountain Alpine Meadows. Acta Agrestia Sin. 2016, 24, 1192-1196.

7. Chen, B.; Feng, X.; Li, X.; Zhang, C. The Retrieval of Snow Depth in Qinghai-Xizang (Tibet) Plateau from Passive Microwave Remote Sensing Data and Its Results Assessment. J. Remote Sens. 2001, 5, 161-165.

8. Hou, H.; Yang, H. A General Introduction to MODIS Snow Products and Its Researching Application. Remote Sens. Technol. Appl. 2009, 24, 252-256. 
9. Zhang, Y.; Huang, X.; Wang, W.; Liang, T. Validation and Algorithm Redevelopment of MODIS Daily Fractional Snow Cover Products. Arid Zone Res. 2013, 30, 808-814.

10. Liu, J.; Chen, R. Studying the MODIS Snow Covered Days by the Use of MODIS Aqua/Terra Snow Cover Products and Insitu Observations in North Eastern and Inner Mongolia Region. Remote Sens. Technol. Appl. 2011, 26, 450-456.

11. Tang, Z.; Wang, J.; Li, H. Accuracy Validation and Cloud Obscuration Removal of MODIS Fractional Snow Cover Products over Tibetan Plateau. Remote Sens. Technol. Appl. 2013, 28, 423-430.

12. Zhang, H.; Zhang, F.; Zhang, G. Ground-based evaluation of MODIS snow cover product V6 across China: Implications for the selection of NDSI threshold. Sci. Total Environ. 2019, 651, 2712-2726. [CrossRef]

13. Wunderle, S.; Gross, T.; Hüsler, F. Snow Extent Variability in Lesotho Derived from MODIS Data (2000-2014). Remote Sens. 2016, 8, 448. [CrossRef]

14. Li, J.; Yang, X.; Xu, B.; Cao, Y.; Qin, Z.; Zhao, L. Snow Monitoring Using MODIS and AMSR-E in Six Main Pastoral Areas of China. Sci. Geogr. Sin. 2011, 31, 1097-1104.

15. Yang, X.; Zheng, Z.; Yang, Z. Validation of AMSR-E Snow Depth Products in Inner Mongolia. Remote Sens. Appl. 2011, 6, 61-68.

16. Wang, W.; Feng, Q.; Zhang, X.; Yu, H.; Lu, Z. Accuracy Analysis of Snow Cover Based on MODIS and AMSR-E in Qinghai Province. J. Glaciol. Geocryol. 2011, 33, 88-100.

17. Yan, H.; Zhang, J. Retrieval of Snow Depth in China by Using SSM/I Data. J. Mt. Sci. 2008, 10, 59-64.

18. Li, X.; Liu, Y.; Zhu, X.; Zheng, Z.; Chen, A. Snow Cover Identification with SSM/I Data in China. J. Appl. Meteorol. Sin. 2007, 18, 12-20.

19. Zhu, Z.; Liu, B.; Feng, S.; Du, Q.; Zhou, B.; Zhou, K. SSM/I based model inversion of snow depth and temporal and spatial distribution of snow cover on the eastern Qinghai-Tibet Plateau. Pratacult. Sci. 2009, 26, 40-46.

20. Nardone, A.; Ronchi, B.; Lacetera, N. Effects of climate changes on animal production and sustainability of livestock systems. Livest. Sci. 2010, 130, 57-69. [CrossRef]

21. Wang, S.; Wei, Y.; Fang, M. Integrated risk assessment of snow disaster in the Three Rivers Source Region, China. Acta Pratacult. Sin. 2014, 23, 108-116.

22. Liu, X.; Liang, T.; Guo, Z.; Zhang, X. Snow disaster warning and risk assessment methods in pastoral areas in northern Xinjiang. Chin. J. Appl. Ecol. 2008, 1, 133-138.

23. Hao, L.; Gao, J.; Yang, C. Snow disaster system of grassland animal husbandry and control countermeasures. Pratacult. Sci. 2006, 23, 48-54.

24. Gong, D.; Li, Z. The Cause of Heavy Snow Disaster Formation and Countermeasure of Decreasing Disaster in the Inner Mongolia. Clim. Environ. Res. 2001, 6, 132-138.

25. Zhang, D.; Zhang, X. Snow disaster-causing mechanism of grasslands in northern China. J. Nat. Disasters 2002, 11, 80-84.

26. Li, D. Risk Assessment of Snow Disaster in Pasturing Area of Inner Mongolia. J. Inner Mong. Meteorol. 2015, 6, 19-23.

27. Fan, J.; Shao, Q.; Wang, J.; Chen, Z.; Zhong, H. An Analysis of Temporal-spatial Dynamics of Grazing Pressure on Grassland in Three Rivers Headwater Region. Chin. J. Grassl. 2011, 33, 64-72.

28. Wang, K.; Hong, F.; Zong, J. Resource Resources and Their Sustainable Utility in the Three-River Headwaters Region. Acta Agrestia Sin. 2005, 13, 28-31.

29. Yang, J.; Jiang, L. Evaluation of snow products over the Tibetan Plateau. Hydrol. Process. 2015, 29, 3247-3260. [CrossRef]

30. Department of Policy and Regulation, China Meteorological Administration. Snow Disaster Level in Pastoral Areas; GB-T 20482-2006 [S]; China Standard Press: Beijing, China, 2006; pp. 1-2.

31. Meteorological Disaster Standard of the Qinghai Provincial Technical Supervision Bureau. Meteorological Disaster Standards; DB63/T372-2001 [S]; China Standard Press: Xining, China, 2001; pp. 6-8.

32. Ma, X.; Huang, X.; Deng, J.; Wang, Y.; Liang, T. Comprehensive risk assessment of snow disasters in Qinghai Province. Acta Pratacult. Sci. 2017, 26, 10-20.

(C) 2019 by the authors. Licensee MDPI, Basel, Switzerland. This article is an open access article distributed under the terms and conditions of the Creative Commons Attribution (CC BY) license (http://creativecommons.org/licenses/by/4.0/). 